\title{
EDITORIAL
}

\section{0 volumes of Marine Ecology Progress Series}

\author{
Otto Kinne* \\ Inter-Research, Nordbünte 23, 21385 Oldendorf/Luhe, Germany
}

Following decades of hard work, Inter-Research (IR) is pleased to celebrate the appearance of the 300th volume of Marine Ecology Progress Series (MEPS). The first volume of MEPS was published in 1979. Volumes 2 and 3 appeared in 1980. The number of volumes then increased to 5 in 1983, 6 in 1984, 7 in 1985 and 10 in 1990. Since 2002 we have been publishing 20 volumes per year, and in 2006, 21 volumes will appear (see also Kinne 2005).

To found an international scientific journal is a challenge; to be permitted to direct it throughout $300 \mathrm{vol}-$ umes is a privilege. To see the journal grow in size and in significance is a pleasure. Over the years it has been possible to attract esteemed editors, authors and reviewers, and to build up a group of high performers on our technical and administrative staff. All these MEPS-associated people have been instrumental in achieving the excellence for which the journal has become known. Here, I wish to thank them most cordially.

We are all grateful to have been able to serve science and society. With the publication of Volume 300 we renew our aim to further develop MEPS and reiterate our intention to strive for excellence. In January 2005 Professor Howard I. Browman was appointed Scientific
Director of IR and Associate Editor-in-Chief of MEPS. I consider these appointments to be of great significance for the future of IR and that of MEPS.

To remain at the forefront of scientific publishing, we are constantly exploring additional avenues of making sound scientific knowledge available to a world-wide audience. Towards this end, we are pleased to introduce an open access initiative for MEPS and our other journals. Details are available in the 'Publisher's Announcement' printed in this MEPS volume.

To further increase the impact of MEPS - and other IR journals - we are initiating a series of IR Symposia. These will address cutting-edge topics in ecology, diseases, climatology, climate impacts, endangered species research, and eco-ethics. IR will provide financial support for key speakers and to assist graduate students and junior scientists. Details on the IR Symposia will be printed in all IR journals and circulated by post and internet as they become available.

\section{LITERATURE CITED}

Kinne O (2005) 25 Years Inter-Research 1979-2004. Mar Ecol Prog Ser 285:1-2 